\title{
Tecnologias Computacionais na Educação: Desafios na Prática Docente
}

\section{Gislaine Lourenço Rocha Figueiredo ${ }^{1}$, Isaura Alcina Martins Nobre ${ }^{1}$, Marize Lyra Silva Passos ${ }^{1}$}

${ }^{1}$ Coordenadoria de Pós-graduação em Informática na Educação - Instituto Federal do Espírito Santo (Ifes) Serra - ES - Brasil

gislaine.lourencorocha@gmail.com,\{isaura,marize\}@ifes.edu.br

\begin{abstract}
This research aimed to analyze, from the perception of teachers, the challenges in teaching practice on the use of computer technology in education. The methodology consists of descriptive exploratory field study, using questionnaire as a data collection instrument. The study showed that the technologies most used by teachers are: internet, email, word processing, presentation software, social networks, projector, multimedia kit and printer / scanner / MFP. The challenges faced by teachers are exploiting the potential of available resources, lack of professionals for the management and maintenance of laboratories, physical and technological infrastructure of laboratories etc.
\end{abstract}

Resumo. Esta pesquisa buscou analisar, a partir da percepção dos professores, os desafios na prática docente diante da utilização de tecnologias computacionais na Educação. A metodologia consiste em pesquisa de campo de caráter exploratório descritivo, com a utilização de questionário como instrumento de coleta de dados. O estudo mostrou que as tecnologias mais utilizadas pelos professores são: internet, email, editor de texto, software de apresentação, redes sociais, projetor, kit multimídia e impressora/scanner/multifuncional. Os desafios enfrentados pelos professores são: explorar as potencialidades dos recursos disponiveis, falta de profissionais para a gestão e manutenção dos laboratórios, infraestrutura fisica e tecnológica dos laboratórios etc. 


\section{Introdução}

Hoje os alunos tem acesso à tecnologias como smartphones, tablets, notebooks, entre outros, e muitos com acesso a internet. Assim, conforme Alarcão “[...] a escola não detém o monopólio do saber. O professor não é o único transmissor do saber e tem de aceitar situar-se nas suas novas circunstâncias que, por sinal, são bem mais exigentes" (2008, p. 16). Conforme a autora, a escola tem que ser uma nova escola, na qual deve haver um pensamento flexível e um sistema aberto ao que a comunidade está inserindo.

O professor necessita dominar o conhecimento quanto às possibilidades de uso de recursos tecnológicos na educação, por meio de formação contínua no decorrer de toda sua carreira profissional. De acordo com Valente: “[...] a questão da formação do professor mostra-se de fundamental importância no processo de introdução da informática na educação, exigindo soluções inovadoras e novas abordagens que fundamentam os cursos de formação." (2002, p. 19). Para o autor, a formação é um requisito necessário para o desenvolvimento da prática pedagógica do professor no ambiente informatizado.

Segundo Marinho, “[...] o computador na escola por si só não provoca mudanças. Com efeito, o computador reproduz o modelo pedagógico tradicional, servindo como uma prolongação do lápis e, quando possível, como um apoio para transmitir informação, confinados em laboratórios de informática.” (2013, p. 268).

Neste cenário escolar que se apresenta é fundamental que os professores procurem melhorias em suas práticas e que sejam capazes de atuar com as Tecnologias de Informação e Comunicação (TIC), criando ambientes de aprendizagem na busca de melhorias no processo de ensino e aprendizagem. Entendemos que diante desta realidade, os procedimentos didáticos devem privilegiar a construção coletiva dos conhecimentos por meio da tecnologia e do uso da Internet. Nas escolas, os alunos têm acesso rápido à informação, e cabe ao professor ser um participante proativo capaz de mediar a aprendizagem por meio da tecnologia.

Este estudo analisa os desafios na prática docente do uso de tecnologias computacionais na educação na percepção de professores do estado do Espírito Santo, e faz parte de um projeto de pesquisa maior denominado "Observatório da Informática na Educação no Estado do Espírito Santo" que tem como objetivo mapear o uso da informática na educação, observando e refletindo quanto aos aspectos de planejamento, execução, avaliação e formação continuada de professores utilizando as TICs como apoio ao processo de ensino-aprendizagem nas escolas do Espírito Santo e dar publicidade aos dados levantados e aos conhecimentos construídos.

\section{Uso de Tecnologias na Educação}

A Tecnologia de Informação e Comunicação (TIC) está presente em todas as atividades humanas na atualidade, e possui a função de acelerar a modernização, mudar a produtividade, além de ampliar a comunicação e informação. Há a sua incorporação em diversos setores da sociedade, inclusive na Educação, na qual possibilita a preparação do cidadão para trabalhar na sociedade do conhecimento, ou sociedade em rede. (ANDRADE, 2002). Esta sociedade é definida por Castells como 
CBIE-LACLO 2015

Anais do XXI Workshop de Informática na Escola (WIE 2015)

[...] uma estrutura social baseada em redes operadas por tecnologias de comunicação e informação fundamentadas na microeletrônica e em redes digitais de computadores que geram, processam e distribuem informação a partir de conhecimento acumulado nos nós dessas redes (2006, p. 20).

A invasão de novas tecnologias, nos dias atuais, tem chegado à área educacional de forma desigual e sem sincronia. Estes aspectos estão interligados entre si, pois a partir do momento que a escola possui equipamentos adequados é necessário que ela tenha um quadro de professores capacitados para lidarem com as TIC, senão se torna um amontoado de máquinas sem utilidade, e ainda, deve possuir uma diretriz curricular que vá de encontro com a realidade da escola, com conteúdos alinhados a melhoria do aprendizado.

A pesquisa da TIC Educação 2013 mostra que 96\% dos professores usam recursos educacionais disponíveis na Internet para preparar aulas. Os recursos mais utilizados são: “[...] imagens, figuras, ilustrações ou fotos (84\%), textos (83\%), questões de prova $(73 \%)$ e vídeos $(74 \%)$. O uso de jogos chega a $42 \%$, apresentações prontas, 41\%, e Programas e softwares educacionais, 39\%." (NIC.br, 2014).

A utilização das TIC na educação não consiste em somente disponibilizar equipamentos, com softwares específicos, ou transmitir conteúdos sob a dependência de um ensino mecânico, mas sim, é necessário que haja metodologias e estratégias para superar o ensino tradicional, atentando-se para o fato de que elas permitirem a construção de conhecimento, pelo uso do fluxo atualizado de informações de forma interativa e cooperativa. As metodologias devem ter como princípio o desenvolvimento cognitivo, emocional, além de propiciar as capacidades e competências de aprender a aprender. (ANDRADE, 2002).

\section{Formação de Professores e Prática Reflexiva}

$\mathrm{Na}$ visão de Alarcão, ser professor reflexivo

[...] implica saber quem sou, as razões pelas quais faço o que faço e conciencializar-me do lugar que ocupo na sociedade. Numa perspectiva de promoção do estatuto da profissão docente, os professores têm de ser agentes activos do seu próprio desenvolvimento e do funcionamento das escolas como organização ao serviço do grande projecto social que é a formação dos educandos. [...] É efectivamente a postura de questionamento que caracteriza o pensamento reflexivo $(1994$, p. 5).

Para Behrens, "[...] a produção de conhecimento com autonomia, com criatividade, com criticidade e espírito investigativo provoca interpretação do conhecimento e não apenas a sua aceitação" (2005, p. 55). Assim, na percepção da autora, o professor deve passar por um processo de mudanças, reformulando suas práticas, sua forma de pensar, de se relacionar e de agir no âmbito educacional, incorporando paradigmas inovadores de educação para atender às novas necessidades que se impõem.

Atualmente, com as novas concepções acerca da aprendizagem e o desenvolvimento acelerado das TIC é preciso que o professor tenha uma formação continuada. Entretanto, o professor não deve apenas ter um aprendizado operacional das TIC, mas sim ele "[...] precisa construir novos conhecimentos; relacionar, relativizar e integrar diferentes conteúdos; (re)significar aquilo que ele sabe fazer com vistas a 
(re)construir um referencial pedagógico na e para uma nova prática." (PRADO; VALENTE, 2002, p. 22).

Prado e Valente defendem a ideia de que o professor deve ter uma formação contextualizada aliando o local que ele atua com a sua prática pedagógica. $\mathrm{O}$ local em que o professor atua deve favorecer "[...] a criação de uma nova cultura na comunidade escolar e propicia o envolvimento dos demais profissionais (professores, coordenadores, gestores e orientadores pedagógicos), que poderão apoiar e mobilizar para a realização de práticas inovadoras" (2002, p. 24). Em relação a sua prática, esta "[...] permite ao professor colocar em ação os pressupostos teóricos e, com isso, perceber a necessidade de relativizá-los, considerando os vários elementos que intervêm no processo de ensino e aprendizagem" (2002, p. 24).

\section{Metodologia}

Para o desenvolvimento do estudo foi realizada uma pesquisa de campo de caráter exploratório descritivo, com a utilização de questionário como instrumento de coleta de dados junto aos professores da rede de ensino público do Espírito Santo, com o intuito de identificar os desafios enfrentados em sua prática docente mediante a utilização dos recursos tecnológicos na Educação.

A pesquisa exploratória é definida por Marconi e Lakatos como uma pesquisa que "[...] tem por objetivo descrever completamente determinado fenômeno [...]" (2003, p. 187), e que "[...] podem ser encontradas tanto descrições quantitativas e/ou qualitativas, quanto acumulação de informações detalhadas, como as obtidas por intermédio da observação participante [...]" (2003, p. 187).

Este tipo de pesquisa tem como objetivo proporcionar maior familiaridade com o problema, com vista a torná-lo mais explícito ou a constituir hipóteses, tendo como objetivo principal o aprimoramento de ideias ou a descoberta de instituições, portanto, seu planejamento é bastante flexível, possibilitando considerações dos mais variados aspectos ao fato estudado (GIL, 2008).

$\mathrm{Na}$ pesquisa de campo, os dados foram obtidos por meio de um questionário online, construído com a ferramenta Google Form. O questionário foi composto de 21 questões, e dividido em 2 partes. Na primeira buscou-se a caracterização do professor, ou seja, identificar o perfil do profissional no qual está sendo investigado; na segunda, a prática pedagógica do professor e o uso de tecnologias na educação, ou seja, como é a prática pedagógica e como estes profissionais lidam com as tecnologias computacionais.

A pesquisa foi realizada nos meses de fevereiro a março de 2015. Em seguida, foi feita a tabulação dos dados e a análise mediante duas categorias: uso de tecnologias computacionais nas escolas do ES; e desafios enfrentados e possibilidades no uso dos recursos tecnológicos.

\section{Análise dos Dados}

\subsection{Caracterização do Professor}

A pesquisa foi realizada entre alunos e ex-alunos do curso de Pós-graduação em Informática na Educação - PIE, no qual os professores da rede pública e privada de 
ensino foram convidados a responder o questionário. O questionário foi enviado pelo Moodle por meio do recurso de mensagens aos participantes do ambiente virtual de aprendizagem do curso pela orientadora deste trabalho. Foram enviados um total de 786 questionários, sendo potenciais respondentes 461 alunos que selecionaram no questionário voltado para análise de perfil do aluno a opção 'magistério' ao item 'Área de atuação (principal atividade que desempenha)'.

Vale ressaltar, que muitos dos ex-alunos talvez não tenham mais o email associado ao AVA Moodle em uso, por isso, não podemos precisar quantas mensagens foram efetivamente entregues. Em resumo, do total de questionários enviados 114 professores puderam contribuir com a pesquisa, um número pequeno, mas considerado suficiente para que essa pesquisa ocorra de forma exploratória, como registro de um estudo preliminar do fenômeno investigado.

A primeira parte buscou caracterizar o professor, onde se obteve os seguintes resultados: a maioria, (46,5\%), é constituída por professores entre 26 e 35 anos, seguida por 36 a 45 anos, (25,4\%), 20 a 25 anos, (11,4\%), 46 a 50 anos, (8,8\%), e acima de 50 anos, $(7,9 \%)$, com uma média de 1 a 5 anos de experiência na Docência, sendo (64\%) do sexo feminino e $(36 \%)$ do sexo masculino; em relação à formação, $(71,9 \%)$ tem formação superior com especialização, $(20,2 \%)$, somente graduação, $(4,4 \%)$ possui mestrado e $(3,5 \%)$ doutorado; quanto à área de atuação temos que $(47,4 \%)$ atuam na rede pública municipal, (30,7\%) atuam na rede pública estadual, (14\%) atuam na rede privada, $(4,4 \%)$ rede pública federal e $(3,5 \%)$ outros; e, a carga horária semanal de trabalho para a maioria dos professores, $(34,2 \%)$ é de $20 \mathrm{~h}$ a $30 \mathrm{~h}$, seguida por $(25,4 \%)$ até $20 \mathrm{~h},(22,8 \%)$ de $30 \mathrm{~h}$ a $40 \mathrm{~h}$ e $(17,6 \%)$ acima de $40 \mathrm{~h}$.

\subsection{Prática Pedagógica e Formação para Uso de Tecnologias Computacionais}

Foi questionado aos professores qual foi o principal resultado alcançado em sua prática pedagógica, e verificou-se que $(50,9 \%)$ das respostas foi tornar as aulas dinâmicas e inovadoras, em seguida, $(18,4 \%)$ responderam incentivar e motivar os alunos, $(11,4 \%) \mathrm{o}$ bom relacionamento com os alunos, (14\%) reconhecimento do seu trabalho pelos alunos e $(5,3 \%)$.

Percebe-se que na atividade docente, é importante que seja destacado como o conhecimento irá chegar aos alunos de forma correta, ou seja, como o professor irá exercer o importante papel de mediador do processo de ensino e aprendizagem, por meio de sua prática pedagógica.

Sobre o principal desafio encontrado no exercício da docência, $(71,1 \%)$ dos professores responderam, que foi transformar a aula em algo prazeroso e interessante, e apenas $(3,5 \%)$ possuem insegurança.

Em relação à curso de formação sobre o uso de tecnologias na educação, $(73,7 \%)$ dos professores responderam que já fizeram algum curso e $(26,3 \%)$ não fizeram nenhum curso voltado para a formação quanto ao uso de tecnologia na educação. Porém $(96,5 \%)$ buscam algum tipo de formação quanto ao uso de tecnologias computacionais em sua prática pedagógica, pois acham importante que o professor obtenha novos saberes docentes.

Diante destes resultados verifica-se que, para os professores pesquisados, há a consciência da importância de uma formação continuada para o seu trabalho como 
docente. A pesquisa mostra que eles têm interesse em investir na sua formação quanto ao uso de tecnologias computacionais, a fim de desenvolver um pensamento reflexivo e crítico, adquirindo assim competências e habilidades fundamentais durante suas atividades docentes.

Além disso, um dos saberes indispensáveis na formação do educador é a produção do saber. Freire afirma que "[...] na formação permanente dos professores, o momento fundamental é o da reflexão crítica sobre a prática. É pensando criticamente a prática de hoje ou de ontem que se pode melhorar a próxima prática" $(2002$, p. 22).

\subsection{Uso de Tecnologias Computacionais nas Escolas}

Percebe-se que em $(84,2 \%)$ das instituições que os professores entrevistados lecionam possuem um local com computador para planejamento de suas aulas, e apenas $(15,8 \%)$ não tem um local adequado. Em (86\%) das escolas há laboratório de informática para utilização dos alunos, no qual somente $(30,7 \%)$ dos professores, utilizam diariamente e $(26,3 \%)$ utilizam 1 a 3 vezes na semana.

A utilização dos laboratórios de informática nas escolas esbarra em algumas dificuldades como: infra-estrutura física e tecnológica inadequada, professores que não foram capacitados a explorar as potencialidades dos recursos disponíveis, e a falta de profissionais para a gestão e manutenção do espaço.

Não se pode ignorar o fato de que "[...] hoje, o uso de tecnologia por jovens e crianças se dá de forma muito natural. Eles convivem com o uso avançado de internet, redes sociais, blogs, twitters e outros (CALDAS et al, 2013, p. 30)". Desta forma “[...] é importante que os professores consigam fazer uso da tecnologia para favorecer a transmissão dos conteúdos, de forma a motivar o aprendizado (CALDAS et al, 2013, p. $30)$ ".

Moran et al, destaca que é fundamental que o professor tenha "[...] uma visão pedagógica inovadora, aberta, que pressupõe a participação dos alunos[...]” (2006, p. 46)". Diante do aparato tecnológico existente, “[...] o professor tem um grande leque de opções metodológicas, de possibilidades de organizar sua comunicação com os alunos, de introduzir um tema, de trabalhar com os alunos presencial e virtualmente, de avaliálos" (2006, p. 32).

Um fato que chama a atenção é sobre a facilidade para utilizar tecnologias computacionais nas aulas, onde $(85,1 \%)$ dos professores responderam que tem facilidade, e apenas $(14,9 \%)$ possuem dificuldade em utilizar estas tecnologias. Vale lembrar que mais de $50 \%$ dos professores têm entre 20 e 35 anos, e que por esse fato devem ter tido um contato maior com a tecnologia e, portanto, mais facilidade de uso.

Em relação aos tipos de recursos tecnológicos utilizados pelos professores, a Tabela 1 cita alguns e apresenta a frequência com que a utilizam: 
CBIE-LACLO 2015

Anais do XXI Workshop de Informática na Escola (WIE 2015)

Tabela 1 - Frequência de utilização dos Recursos Tecnológicos

\begin{tabular}{|l|c|c|c|c|c|}
\hline \multirow{2}{*}{\multicolumn{1}{|c|}{ Recursos Tecnológicos }} & \multicolumn{5}{|c|}{ Frequência de Utilização } \\
\cline { 2 - 6 } & Nunca & Raramente & Frequentemente & Quase Sempre & Sempre \\
\hline \hline Internet & $3,5 \%$ & $3,5 \%$ & $11,4 \%$ & $11,4 \%$ & $70,2 \%$ \\
\hline Email & $8,8 \%$ & $6,1 \%$ & $10,5 \%$ & $15,8 \%$ & $58,8 \%$ \\
\hline Ferramenta de Desenho & $10,5 \%$ & $34,2 \%$ & $28,9 \%$ & $13,2 \%$ & $13,2 \%$ \\
\hline Editor de Texto & $3,5 \%$ & $2,6 \%$ & $7,9 \%$ & $17,5 \%$ & $68,4 \%$ \\
\hline Software de Apresentação & $2,6 \%$ & $7,9 \%$ & $21,1 \%$ & $20,2 \%$ & $48,2 \%$ \\
\hline Planilha Eletrônica & $12,3 \%$ & $19,3 \%$ & $20,2 \%$ & $25,4 \%$ & $22,8 \%$ \\
\hline Jogos Educativos & $12,3 \%$ & $27,2 \%$ & $21,1 \%$ & $14,0 \%$ & $25,4 \%$ \\
\hline Outros Jogos & $21,9 \%$ & $38,6 \%$ & $14,0 \%$ & $9,6 \%$ & $15,8 \%$ \\
\hline Vídeos/Filmes & $0,9 \%$ & $7,9 \%$ & $33,3 \%$ & $25,4 \%$ & $32,5 \%$ \\
\hline Ferramentas de Comunicação & $27,2 \%$ & $24,6 \%$ & $19,3 \%$ & $9,6 \%$ & $19,3 \%$ \\
\hline Redes Sociais & $18,4 \%$ & $15,8 \%$ & $14,9 \%$ & $21,9 \%$ & $28,9 \%$ \\
\hline Projetor Multimídia & $5,3 \%$ & $8,8 \%$ & $16,7 \%$ & $23,7 \%$ & $45,6 \%$ \\
\hline Lousa Digital & $64,0 \%$ & $7,9 \%$ & $7,0 \%$ & $11,4 \%$ & $9,6 \%$ \\
\hline Kit Multimídia & $12,3 \%$ & $14,9 \%$ & $25,4 \%$ & $20,2 \%$ & $27,2 \%$ \\
\hline $\begin{array}{l}\text { Impressora/Scanner/Multifunciona } \\
\text { I }\end{array}$ & $14,9 \%$ & $10,5 \%$ & $14,0 \%$ & $16,7 \%$ & $43,9 \%$ \\
\hline $\begin{array}{l}\text { Ambientes } \\
\text { Aprendizagem }\end{array}$ & $29,8 \%$ & $14,9 \%$ & $12,3 \%$ & $14,9 \%$ & $28,1 \%$ \\
\hline $\begin{array}{l}\text { Criação de Sites/Páginas } \\
\text { Internet }\end{array}$ & $26,3 \%$ & $36,0 \%$ & $13,2 \%$ & $7,9 \%$ & $16,7 \%$ \\
\hline Livre escolha do aluno & na & $35,1 \%$ & $22,8 \%$ & $5,3 \%$ & $12,3 \%$ \\
\hline
\end{tabular}

Verifica-se que os recursos mais utilizados pelos professores são: internet, email, editor de texto, software de apresentação, redes sociais, projetor multimídia, kit multimídia e impressora/scanner/multifuncional, e os nunca utilizados são ferramentas de comunicação, lousa digital e ambientes virtuais de aprendizagem.

Mas, apesar da maioria dos professores ter facilidade no uso das tecnologias computacionais, pois muitos deles são graduados ou possuem pós-graduação na área de informática, eles comentaram em suas respostas que se deparam com algumas dificuldades para aplicação em sala de aula, como infraestrutura inadequada, comprometimento dos alunos em sala de aula, entre outros. Seguem alguns comentários:

"Tenho facilidade em utilizar as tecnologias, porém não em minhas aulas, pois a instituição em que atuo não possui os recursos tecnológicos necessários para colaborar com as aulas."

"Com relação ao meu conhecimento, posso dizer que não tenho dificuldade para utilizá-los, porém, às vezes nos deparamos com situações onde a própria instituição escolar não proporciona estes recursos."

"Os alunos da rede municipal de Vila Velha tem em sua grade curricular a disciplina 'Tecnologia Educacional' e além dessas aulas, como professora TE, auxilio, nas 
diversas disciplinas, no planejamento com os professores regentes do ensino fundamental I. Ainda encontro muita resistência de alguns professores, principalmente os que não tem conhecimento do contexto tecnológico.

Percebe-se que os professores possuem conhecimento sobre a utilização de recursos tecnológicos, porém fatores como infraestrutura da escola, que muitas vezes é inadequada, computadores antigos, internet lenta, laboratórios de informática que não funcionam dificultam o trabalho com as tecnologias computacionais em sala de aula.

\subsection{Desafios mediante a Utilização de Recursos Tecnológicos na Educação}

Os professores citam como desafios: a estrutura inadequada da escola para o uso destas tecnologias, falta de preparo para o manuseio de forma proveitosa, acesso à internet, motivação dos alunos etc. Seguem comentários de alguns dos professores pesquisados:

"O baixo investimento em tecnologia, principalmente nas escolas públicas. E também a resistência de alguns professores."

"Diante toda a transformação e explosão de informações em que os jovens estão inseridos o principal desafio é mostrar para eles como utilizar as tecnologias de modo eficiente, de maneira que possa ajudá-los a transformar os conteúdos estudados em algo interessante e de fácil compreensão, quando utilizado de pesquisas corretas através de links e hipertexto. Outro grande desafio são as diversas distrações existentes na rede e que muitas vezes o aprendiz se perde neste meio."

"Os desafios são: os recursos para a realização do uso da informática, falta de capacitação da maioria dos docentes e tempo para o desenvolvimento de tarefas voltadas para o uso das tecnologias."

"Os maiores desafios são transformar as tecnologias em ferramentas de aprendizagem para nossas aulas. Para isso, um planejamento com qualidade, em parceria com os demais professores e pedagogos, pode fomentar nos alunos novas aprendizagens a partir do uso das tecnologias."

Diante do exposto, pode-se dizer que os maiores desafios encontrados pelos professores na utilização de recursos tecnológicos são:

a) Infraestrutura da escola inadequada para a utilização das TICs - apesar da maioria das escolas, que os professores participantes da pesquisa lecionam, possuir laboratório de informática, percebe-se que a infraestrutura não atende de forma satisfatória, além da falta de um técnico ou instrutor para gestão dos laboratórios, ao qual o professor possa se reportar e ter apoio quanto aos aspectos tecnológicos.

b) Facilidade de dispersão do aluno - a utilização de ferramentas tecnológicas na aula é uma situação de aprendizado nova e muitos alunos não conseguem assimilar esta nova forma de aprender, pois, conforme Moran et al "[...] estão acostumados a receber tudo pronto do professor, e esperam que ele continue 'dando aula', como sinônimo de ele falar e os alunos escutarem [...]" (2006, p. 54). Em uma aula no Laboratório de Informática, por exemplo, onde são disponibilizados computadores com acesso a Internet para utilização do alunos, Moran afirma que "[...] há facilidade de dispersão. Muitos alunos se perdem no emaranhado de possibilidades de navegação. Não procuram 
o que foi combinado, deixando-se arrastar para áreas de interesse pessoal [...]” (2006, p. 54).

A intervenção do professor se faz necessária, quando é utilizado o acesso à internet na aula. Cabe ao professor mediar e levar o aluno a saber realizar adquadamente pesquisas, selecionando conteúdos e navegando sem perder o foco dos objetivos da aula.

c) Uso potencial dos recursos tecnológicos no processo de ensino e aprendizagem apesar da maioria dos professores participantes da pesquisa possuir conhecimento acerca das ferramentas tecnológicas, muitos têm dificuldade quanto ao seu potencial uso pedagógico.

Mas os professores pesquisados esbarram em outro desafio, a falta de tempo para o planejamento de suas aulas com o uso de recursos computacionais, visto que a docência é uma profissão que demanda muito tempo do docente.

\section{Aspectos Conclusivos}

A pesquisa objetivou analisar, a partir da percepção dos professores, os desafios na prática docente diante da utilização de tecnologias computacionais na Educação e se desenvolveu a partir de uma revisão bibliográfica e pesquisa de campo de caráter exploratório descritivo, com a utilização de questionário como instrumento de coleta de dados.

Assim, pelas análises realizadas foi possível identificar as tecnologias mais utilizadas pelos professores, bem como, os desafios enfrentados em sua prática docente.

Concluiu-se que as tecnologias mais utilizadas pelos professores de algumas instituições de ensino do Espírito Santo são: internet, email, editor de texto, software de apresentação, redes sociais, projector multimídia e impressora/scanner/multifuncional.

Em relação aos desafios, por eles enfrentados, mediante à utilização das tecnologias em sua prática pedagógica estão: infraestrutura física e tecnológica inadequada, exploração das potencialidades dos recursos disponíveis, falta de profissionais para a gestão e manutenção dos laboratórios e facilidade de dispersão do aluno. Acredita-se que mesmo diante das dificuldades apresentadas, o professor deve buscar caminhos, com os recursos disponíveis, para utilização em sua prática pedagógica.

Outro desafio apontado pelos professores em sua prática pedagógica, mediante a utilização dos recursos tecnológicos, foi o uso potencial destes recursos no processo de ensino e aprendizagem. Apesar dos professores terem conhecimento acerca das ferramentas tecnológicas, eles têm pouco tempo para planejamento das aulas, dificultando o uso potencial das mesmas.

\section{Referências}

Alarcão, I. (2008) "Professores Reflexivos em uma Escola Reflexiva”. 6 Ed. São Paulo: Cortez.

(1994) "Ser professor reflexivo". Disponível em: $<$ http://www.alemdasletras.org.br/biblioteca/artigo_especializados/Ser_professor_refl exivo_Isabel_Alarcao.pdf $>$. Acesso em 09 dez 2014. 
Almeida, F. J. de; Franco, M. G. (2014) "Tecnologias para a Educação e Políticas Curriculares de Estado". In: Pesquisa sobre o uso das tecnologias de informação e comunicação nas escolas brasileiras: TIC Educação 2013. $1^{a}$ Ed. São Paulo: Comitê Gestor da Internet no Brasil. Disponível em: $<$ http://www.cetic.br/pesquisa/educacao/publicacoes> Acesso em 09 dez 2014.

Andrade, P. F. (2002) "Aprender por Projetos, Formar Educadores". In: Valente, J. A. (Org.) Formação de Educadores para o uso da Informática na Escola. São Paulo: Unicamp.

Behrens, M. A.. (2005) “O Paradigma emergente e a prática pedagógica”. 2. ed. Petrópolis, RJ: Vozes.

Caldas, W. K.; Nobre, I. A. M.; Gava, T. B. S. "Uso do computador na educação: desafios tecnológicos e pedagógicos" (2013). In: Nobre, I. A. M.; Nunes, V. B.; Gava, T. B. S.; Fávero, R. da P.; Bazet, L. M. B. (Org.). Informática na Educação: um caminho de possibilidades e desafios. Serra: IFES.

Castells, M. (2006) “A sociedade em Rede”. São Paulo: Paz e Terra.

Freire, Paulo. (2002) "Pedagogia da Autonomia: saberes necessários à prática educative". São Paulo.

Gil, A. C. (2008) "Métodos e Técnicas de Pesquisa Social”. 6ª ed. São Paulo: Atlas.

Marconi, M. de A.; Lakatos, E. M. (2003) "Fundamentos de Metodologia Científica”. 5 ed. São Paulo: Atlas.

MARINHO, Vanessa. "O Cenário do Uso das Tecnologias na Escola do Século XXI". II Congresso Brasileiro de Informática na Educação (CBIE 2013) e XIX Workshop de Informática na Escola (WIE 2013). Anais 2013. Disponível em: $<$ http://www.brie.org/pub/index.php/wie/article/view/2605/2261>. Acesso em: mai de 2015.

Moran, J. M.; Masetto, M. T.; Behrens, M. A.(2006) "Novas tecnologias e mediação pedagógica". Campinas, SP: Papirus.

NIC.br, 2014. (2014) "TIC Educação 2013 revela aumento do uso do computador e Internet na sala de aula". Disponível em: $<$ http://www.nic.br/imprensa/releases/2014/rl-2014-22.htm> Acesso em 09 dez 2014.

Prado, M. E. B. B.; Valente, J. A. (2002) "A Formação na Ação do Professor: Uma Abordagem na e para uma Nova Prática Pedagógica”. In: VALENTE, José Armando. (Org.) Formação de Educadores para o uso da Informática na Escola. São Paulo: Unicamp.

Valente, J. A. (2002) "Criando ambientes de aprendizagem via rede telemática: experiências na formação de professores para o uso da informática na educação". In: Valente, J. A. (Org.) Formação de Educadores para o uso da Informática na Escola. São Paulo: Unicamp. 